\title{
Identification and response analysis of xyloglucan endotransglycosylase/ hydrolases (XTH) family to fluoride and aluminum treatment in Camellia sinensis
}

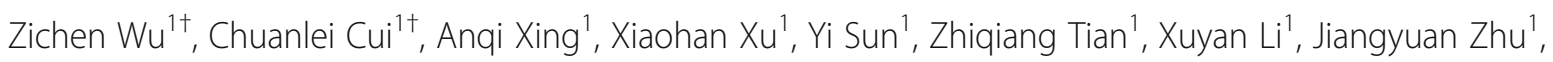
Genmei Wang ${ }^{2}$ and Yuhua Wang ${ }^{1 *}$

\begin{abstract}
Background: Xyloglucan endotransglycosylase/hydrolases (XTH) can disrupt and reconnect the xyloglucan chains, modify the cellulose-xyloglucan complex structure in the cell wall to reconstruct the cell wall. Previous studies have reported that XTH plays a key role in the aluminum (Al) tolerance of tea plants (Camellia sinensis), which is a typical plant that accumulates $\mathrm{Al}$ and fluoride $(\mathrm{F})$, but its role in $\mathrm{F}$ resistance has not been reported.

Results: Here, 14 CSXTH genes were identified from C. sinensis and named as CSXTH1-14. The phylogenetic analysis revealed that CSXTH members were divided into 3 subclasses, and conserved motif analysis showed that all these members included catalytic active region. Furthermore, the expressions of all CSXTH genes showed tissue-specific and were regulated by $\mathrm{Al}^{3+}$ and $\mathrm{F}^{-}$treatments. CSXTH1, CSXTH4, CSXTH6-8 and CSXTH11-14 were up-regulated under $\mathrm{Al}^{3+}$ treatments; CSXTH1-10 and CSXTH12-14 responded to different concentrations of $\mathrm{F}^{-}$treatments. The content of xyloglucan oligosaccharide determined by immunofluorescence labeling increased to the highest level at low concentrations of $\mathrm{Al}^{3+}$ or $\mathrm{F}^{-}$treatments $\left(0.4 \mathrm{mM} \mathrm{Al}{ }^{3+}\right.$ or $\left.8 \mathrm{mg} / \mathrm{LF}^{-}\right)$, accompanying by the activity of XET (Xyloglucan endotransglucosylase) peaked.

Conclusion: In conclusion, CSXTH activities were regulated by Al or F via controlling the expressions of CSXTH genes and the content of xyloglucan oligosaccharide in C. sinensis roots was affected by Al or F, which might finally influence the elongation of roots and the growth of plants.
\end{abstract}

Keywords: Camellia sinensis, Xyloglucan endotransglycosylase/hydrolases (XTH), Aluminum, Fluoride

\section{Background}

The tea plant [Camellia sinensis (L.) O. Kuntze] is one of the economic crops in China, which can be processed into an important non-alcoholic beverage [1]. Tea plants can accumulate large amounts of aluminum (Al) and fluoride (F), which are partially dissolved in the tea soup

\footnotetext{
* Correspondence: wangyuhua@njau.edu.cn

${ }^{\dagger}$ Zichen Wu and Chuanlei Cui contributed equally to this work.

${ }^{1}$ College of Horticulture, Nanjing Agricultural University, Nanjing 210095, China

Full list of author information is available at the end of the article
}

[2]. Excessive $\mathrm{Al}$ intake over the long term is easy to induce Alzheimer's disease and excessive $\mathrm{F}$ intake may cause serious health problems [2, 3]. Therefore, the study on the mechanism of absorption and accumulation of $\mathrm{Al}$ and $\mathrm{F}$ in $C$. sinensis plays a vital role in providing theoretical basis for reducing the content of $\mathrm{Al}$ and $\mathrm{F}$ and improving the quality of tea.

The mechanism of $\mathrm{Al}$ and $\mathrm{F}$ accumulation is closely related to the construction of cell walls in C. sinensis. As a thick wall existing in the periphery of cells, cell wall is

(c) The Author(s). 2021 Open Access This article is licensed under a Creative Commons Attribution 4.0 International License, which permits use, sharing, adaptation, distribution and reproduction in any medium or format, as long as you give appropriate credit to the original author(s) and the source, provide a link to the Creative Commons licence, and indicate if changes were made. The images or other third party material in this article are included in the article's Creative Commons licence, unless indicated otherwise in a credit line to the material. If material is not included in the article's Creative Commons licence and your intended use is not permitted by statutory regulation or exceeds the permitted use, you will need to obtain permission directly from the copyright holder. To view a copy of this licence, visit http://creativecommons.org/licenses/by/4.0/ The Creative Commons Public Domain Dedication waiver (http://creativecommons.org/publicdomain/zero/1.0/) applies to the data made available in this article, unless otherwise stated in a credit line to the data. 
the first to sense environmental stress. In the process of the growth and differentiation of cells, the cell walls must be relaxed and extended before the elongation of roots. Previous studies have shown that $\mathrm{Al}$ in $\mathrm{C}$. sinensis is mainly accumulated in the cell walls. The more mature the leaf is, the thicker the cell wall is and the higher the content of $\mathrm{Al}$ is [4]. The combination of $\mathrm{Al}$ with the cell walls of roots can reduce the elasticity and hydraulic conductivity of cell walls, inhibiting root elongation. In addition, studies have shown that enrichment of $\mathrm{F}$ in the cell wall can prevent $\mathrm{F}$ from entering cells, which is an important mechanism of $\mathrm{F}$ tolerance in $\mathrm{C}$. sinensis $[5,6]$.

Xyloglucan endotransglycosyltransferase/hydrolase (XTH) widely exists in various plant tissues, and catalyzes the cleavage and polymerization of xyloglucan molecules, thereby remodeling the cell wall cellulosexyloglucan complex structure, enabling cell wall remodeling [7]. This process can minimize the resistance and promote the elongation of cells to help cell walls loosen and expand. In addition, XTH can also catalyze the transfer of newly synthesized xyloglucan molecules to the original cell wall network structure in order to maintain the thickness and integrity of the cell wall during reconstitution [8]. XTHs belongs to glycoside hydrolase family (GH16), and the most suitable substrate is xyloglucan, which mainly exerts two activities: one is xyloglucan endotransglucosylase (XET) activity, which catalyzes the cleavage of the p-1, 4-glycosidic bond in the xyloglucan molecule and transfers the resulting glycosyl terminus to the non-reducing end of another xyloglucan or oligosaccharide. And the other is xyloglucan hydrolase (XEH) activity, which catalyzes the hydrolysis of xyloglucan [8-11]. XTHs are a class of proteins encoded by multiple genes that were originally divided into three subfamilies, I, II and III. Yokoyama et al. (2004) compared the XTH sequences in the whole genome of Oryza sativa and Arabidopsis thaliana and found no significant difference between subfamilies I and II, so they were combined and named as I/II [12]. Baumann et al. (2007) also classified subfamilies III into two subgroups, IIIA and IIIB, respectively, based on their catalytic activity [13]. Previous studies have shown that members of subfamilies I, II, and IIIB exert XET activity primarily [14-17].

In recent years, the response of XTHs to stress has become the focus of researchers' attention because XTHs are a class of genes that regulate cell elongation and expansion during the growth of plants $[18,19]$. For example, 3 homologous genes, CaXTH1, CaXTH2 and CaXTH3, were found in Capsicum annuum to cope with stress such as drought, high salt and low temperature [20]. Yang et al. (2011) reported that heavy metal $\mathrm{Al}^{3+}$ stress significantly down-regulated the transcriptional expression of AtXTH14, AtXTH15 and AtXTH31 in A. thaliana, which would reduce the activity of XET, resulting in a significant inhibition of root elongation [21]. As a result of the important role of cell walls playing in the process of $\mathrm{Al}$ and $\mathrm{F}$ accumulation and resistance in plants, the function of XTHs is also of great significance in the study of the molecular mechanism of this process. To reveal the effects of CsXTHs on cell wall reconstruction under $\mathrm{Al}$ and $\mathrm{F}$ treatments in $C$. sinensis, we analyzed the bioinformatics characteristics of $C s X T H \mathrm{~s}$, measured the expression levels of CsXTHs, the content of xyloglucan and xyloglucan oligosaccharide, and determined XET activities under $\mathrm{Al}$ and $\mathrm{F}$ treatments in the present study.

\section{Results}

Identification and phylogenetic tree analysis of XTHs in C. sinensis

Based on the transcriptomic databases of C. sinensis, 45 $X T H s$ sequences were screened [22]. After further verification by BLAST program and ClustalX 1.83 software, $14 \mathrm{Cs} X T H$ genes were identified and renamed as CsXTH1 to CsXTH14.

The phylogenetic tree was constructed with 14 CsXTHs proteins in C. sinensis and 33 AtXTHs proteins in A. thaliana. All XTHs proteins were divided into three subclasses (subclasses I, II, and III). There were 4 CsXTH members (CsXTH6, CsXTH7, CsXTH11 and CsXTH14) and 11 AtXTH members (AtXTH1-11) belonging to subclass I. And $4 \mathrm{CsXTH}$ members (CsXTH2, CsXTH4, CsXTH5 and CsXTH13) and 15 AtXTH members (AtXTH12-26) belonged to subclass II. Subclass III could be divided into IIIA and IIIB, of which subclass IIIA contained 3 CsXTH members (CsXTH1, CsXTH3 and CsXTH9) and 2 AtXTH members (AtXTH31-32), subclass IIIB contained 3 CsXTH members (CsXTH8, CsXTH10 and CsXTH12) and 5 AtXTH members (AtXTH2730 and AtXTH33) (Fig. 1).

The physicochemical characteristics of $14 \mathrm{CsXTH}$ proteins were further analyzed. The number of amino acids (a) of CsXTH proteins varied from 287 (CsXTH13) to 477 (CsXTH12), and their molecular weights ranged from 32,262.41 to 54,695.61 (Table 1). The theoretical isoelectric points of CsXTHs varied from 4.82 (CsXTH6) to 9.92 (CsXTH12) (Table 1). The grand averages of hydropathicity (GRAVY) of CsXTHs were negative, so all CsXTH proteins were hydrophilic. The results of instability index of $14 \mathrm{CsXTHs}$ showed that CsXTH proteins from subclass I were all stable and $\mathrm{CsXTH}$ proteins from subclass III (IIIA and IIIB) were all unstable. Half of members (CsXTH2 and CsXTH4) of subclass II were unstable, and the others (CsXTH5 and CsXTH13) were stable. 


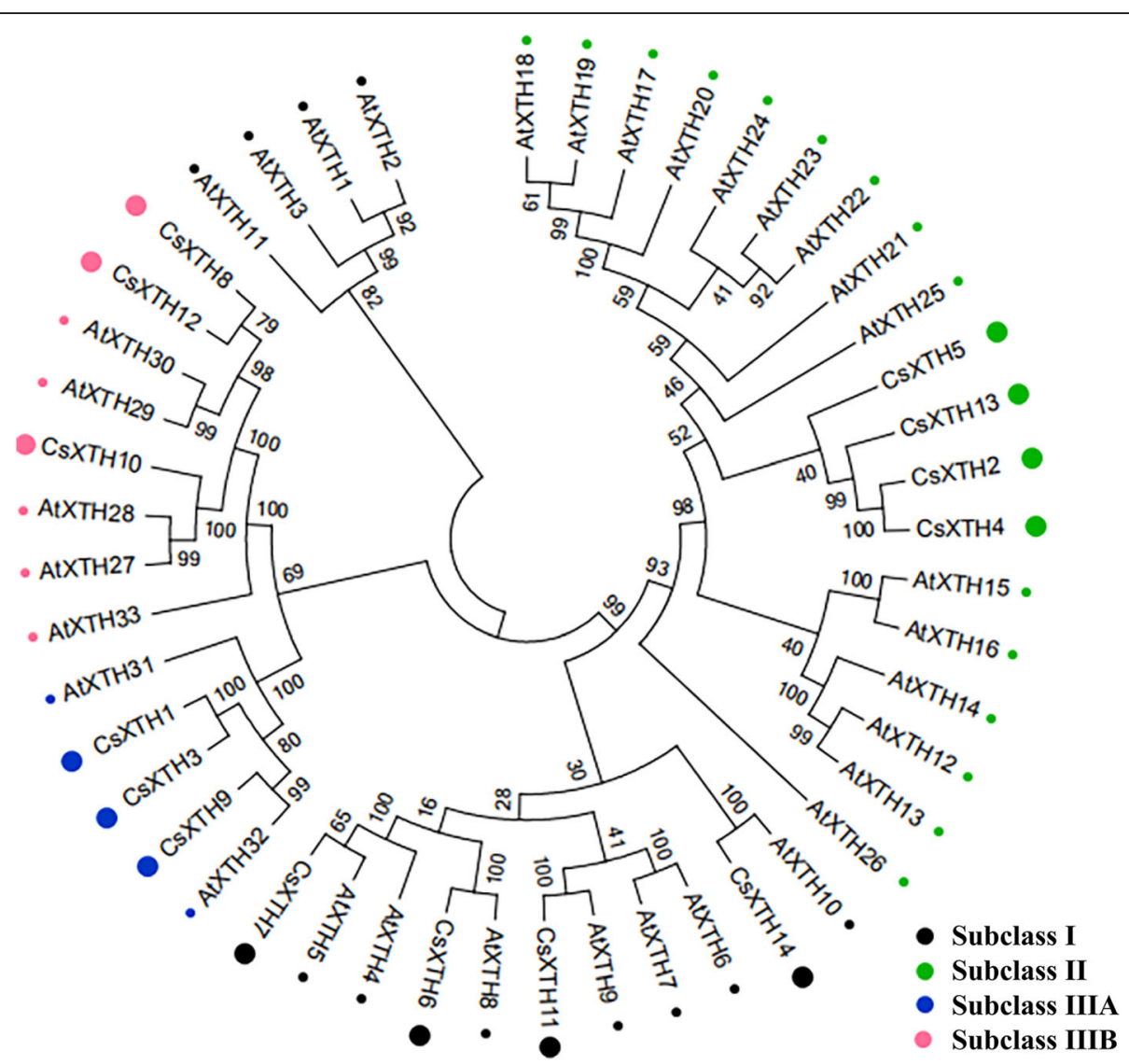

Fig. 1 The phylogenetic tree of XTHs members from Camellia sinensis and Arabidopsis thaliana. Different subclasses are marked with dots of different colors (black dots: subclass I; green dots: subclass II; blue dots: subclass IIIA; pink dots: subclass IIIB)

Table 1 Physicochemical characteristics of XTHs in C. sinensis

\begin{tabular}{llllll}
\hline Protein Name & Number of amino acids & Molecular weight & Theoretical pl & Instability index & Grand average of hydropathicity (GRAVY) \\
\hline CSXTH1 & 291 & $32,869.60$ & 5.33 & 49.63 & -0.469 \\
CSXTH2 & 289 & $32,401.32$ & 5.57 & 44.11 & -0.313 \\
CSXTH3 & 291 & $32,831.56$ & 5.95 & 45.29 & -0.529 \\
CSXTH4 & 290 & $32,553.36$ & 5.38 & 44.71 & -0.363 \\
CSXTH5 & 333 & $37,996.93$ & 8.74 & 32.97 & -0.498 \\
CSXTH6 & 299 & $34,894.80$ & 4.82 & 34.44 & -0.543 \\
CSXTH7 & 295 & $34,061.39$ & 7.65 & 33.85 & -0.467 \\
CSXTH8 & 341 & $39,371.45$ & 8.88 & 40.92 & -0.560 \\
CSXTH9 & 295 & $34,104.87$ & 9.47 & 53.64 & -0.393 \\
CSXTH10 & 329 & $37,275.84$ & 6.31 & 42.98 & -0.500 \\
CSXTH11 & 297 & $33,850.12$ & 5.87 & 37.70 & -0.301 \\
CSXTH12 & 477 & $54,695.61$ & 9.92 & 54.08 & -0.532 \\
CSXTH13 & 287 & $32,262.41$ & 8.18 & 36.45 & -0.310 \\
CSXTH14 & 298 & $34,590.05$ & 6.08 & 30.39 & -0.403 \\
\hline
\end{tabular}


Gene structure, conserved motifs and sequence alignment analysis of CsXTHs

The gene structures of $14 \mathrm{Cs} X T H s$ showed that $\mathrm{Cs} X T H$ genes from subclass I and subclass III (IIIA and IIIB) all had 4 exons (Fig. 2). CsXTH5 had only 1 exon and other genes of subclass II (CsXTH2, CsXTH4 and CsXTH13) all had 3 exons (Fig. 2).

There were 7 conserved motifs (motif $1-7$ ) in all 14 CsXTHs. The conserved motif 4 contained the catalytic sequence motif of the XTH proteins (HDEIDFEFLG) (Fig. 3). And the logo of catalytic sequence motif (HDEI DFEFLG) of CsXTHs was shown in Fig. 4 [23]. Motif 14 was exclusively present in CsXTHs of subclass I, and motif 12 was only existed in CsXTHs of subclass II (Fig. 3). In addition, motif 9, 11 and 13 were only present in $\mathrm{CsXTH}$ proteins of subclass IIIA, and motif 15 was exclusively existed in CsXTH proteins of subclass IIIB (Fig. 3).

The multiple sequence alignments of $14 \mathrm{CsXTH}$ proteins indicated that all CsXTH proteins contained the conserved sequence (HDEIDFEFLG) (black rounded rectangular frames) except there were deviations of 1 or 2 amino acids in few sequences (Fig. 5) [23]. Except for all CsXTHs from subclass IIIA (CsXTH1, CsXTH3 and CsXTH9), the catalytic active regions (HDEIDFEFLG) of $\mathrm{CsXTH}$ proteins were followed by amino acids of asparagine $(\mathrm{N})$, which were the $\mathrm{N}$-linked glycosylation sites (Fig. 5) [24]. Moreover, conserved Cys residues were present in C-terminal of sequences of all $14 \mathrm{CsXTH}$ proteins (black rectangular frames) (Fig. 5).

\section{The relative expression levels of CSXTHs in different tissues}

The relative expression levels of $14 \mathrm{Cs} X T H$ genes in different tissues (root, stem, old leaf, young leaf, flower, pollen and fruit) of $C$. sinensis cv. Longjing 43 were analyzed by qRT-PCR. The results showed that the expression of $14 \mathrm{Cs} X T H$ genes in different tissues of $\mathrm{C}$. sinensis was significantly different, but the expression level showed certain regularity. CsXTH2, CsXTH3, CsXTH8 and $C s X T H 13$ were highly expressed in roots of $C$. sinensis. The expression levels of CsXTH2, CsXTH3, CsXTH7, CsXTH9 and CsXTH11 in stems were relatively high. CsXTH3, CsXTH6, CsXTH10 and CsXTH11 had higher expression level in young leaves of $C$. sinensis. CsXTH1, CsXTH4, CsXTH5, CsXTH6, CsXTH7, CsXTH11, CsXTH12 and CsXTH14 were highly expressed in flowers. The expression level of CsXTH12 in pollens was higher than other genes. In fruits of $C$. sinensis, CsXTH1, CsXTH4, CsXTH5 and CsXTH7 were highly expressed. It was noteworthy that $14 \mathrm{Cs} X T H$ genes all showed low expression levels in old leaves (Fig. 6). This result indicated that the expressions of CsXTHs are tissue-specific.

\section{The relative expression levels of CsXTHs under $\mathrm{Al}^{3+}$ treatment}

The CsXTH family showed different expression profiles in response to $\mathrm{Al}^{3+}$ treatments of different concentrations. The expressions of CsXTH2, CsXTH3, CsXTH5, CsXTH6 and CsXTH12 were upregulated under $0.1 \mathrm{mM}$ $\mathrm{Al}^{3+}$ treatment. The expression levels of CsXTH7, CsXTH9, CsXTH13 and CsXTH14 significantly increased under $0.4 \mathrm{mM} \mathrm{Al}{ }^{3+}$ treatment. The expressions of CsXTH1, CsXTH3, CsXTH5 and CsXTH8 were upregulated under $2.0 \mathrm{mM} \mathrm{Al}^{3+}$ and then declined at $4 \mathrm{mM}$ $\mathrm{Al}^{3+}$ treatment. The expressions of CsXTH5, CsXTH11 and $C s X T H 13$ were downregulated under $4.0 \mathrm{mM} \mathrm{Al}^{3+}$ treatment, while CsXTH4 and $C s X T H 10$ were upregulated under the treatment of $4.0 \mathrm{mM} \mathrm{Al}^{3+}$ (Fig. 7).

\section{The relative expression levels of $\mathrm{Cs} X T H s$ under $\mathrm{F}^{-}$ treatment}

In the present study, the relative expression levels of 14 $\mathrm{Cs} X T H$ genes in roots under $0 \mathrm{mg} / \mathrm{L}, 8 \mathrm{mg} / \mathrm{L}$ and $16 \mathrm{mg} /$

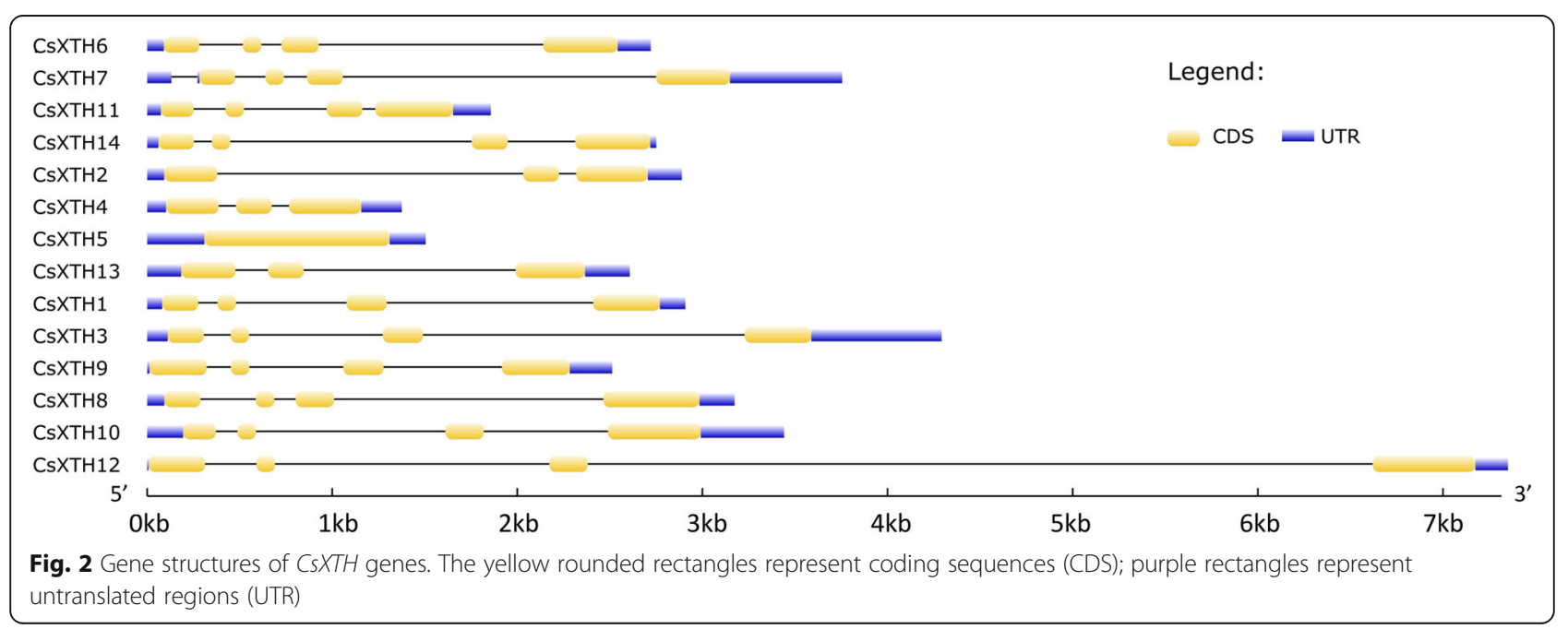




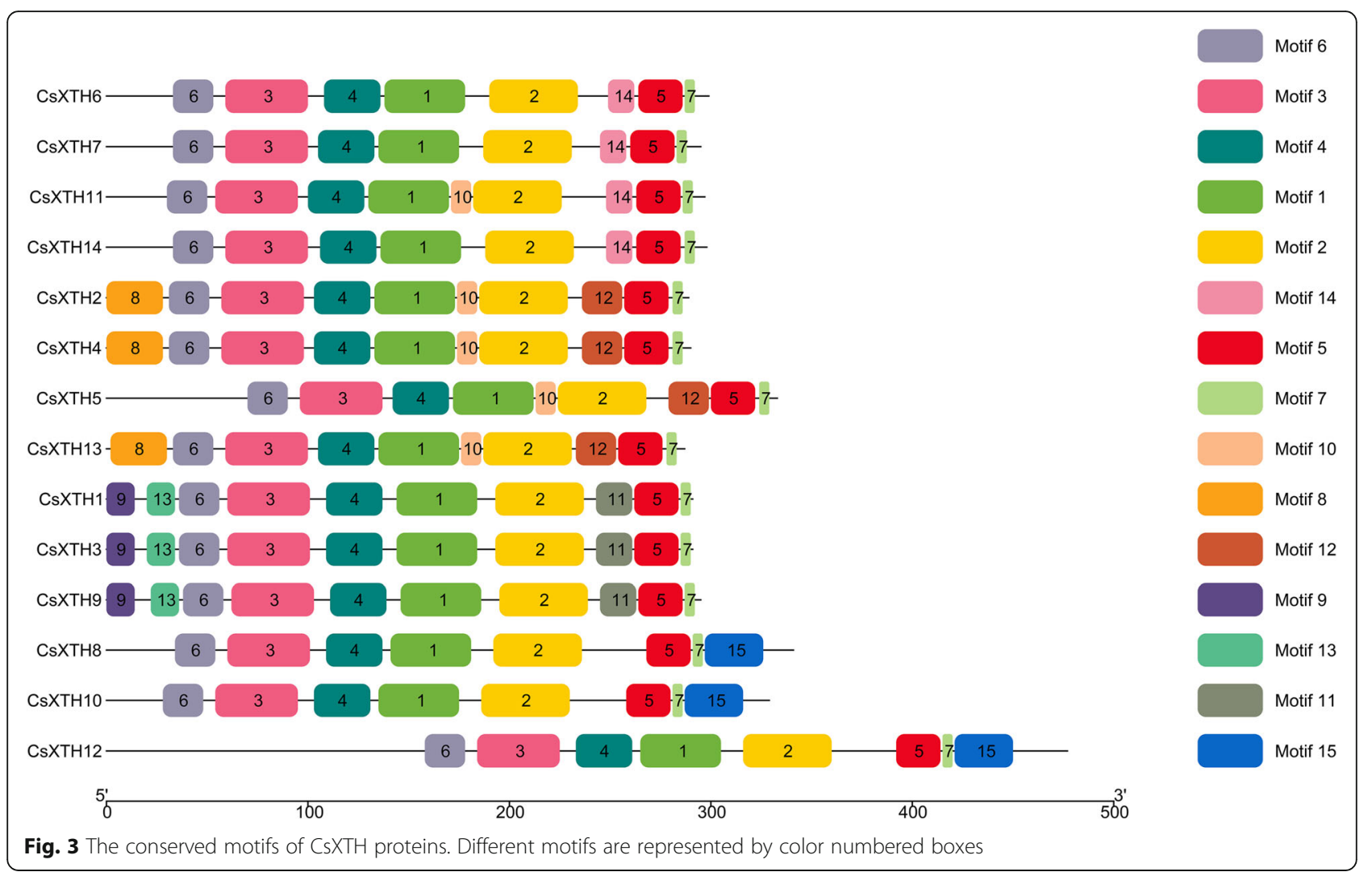

$\mathrm{LF}^{-}$treatment were analyzed, and the results were shown in Fig. 8. The expressions of CsXTH1, CsXTH4, CsXTH6, CsXTH7, CsXTH8, CsXTH12, CsXTH13 and CsXTH14 increased to the maximum levels at $8 \mathrm{mg} / \mathrm{L} \mathrm{F}^{-}$ treatment. However, the expressions of $\mathrm{CsXTH2}$ and
CsXTH5 decreased at $8 \mathrm{mg} / \mathrm{L} \mathrm{F}^{-}$and then slightly increased at $16 \mathrm{mg} / \mathrm{L} \mathrm{F}^{-}$. Furthermore, CsXTH2, CsXTH5 and $C s X T H 11$ all showed higher expression levels at 16 $\mathrm{mg} / \mathrm{L} \mathrm{F}^{-}$treatment compared to that under $8 \mathrm{mg} / \mathrm{L} \mathrm{F}^{-}$ treatment. Compared with the control $\left(0 \mathrm{mg} / \mathrm{L} \mathrm{F}^{-}\right)$,

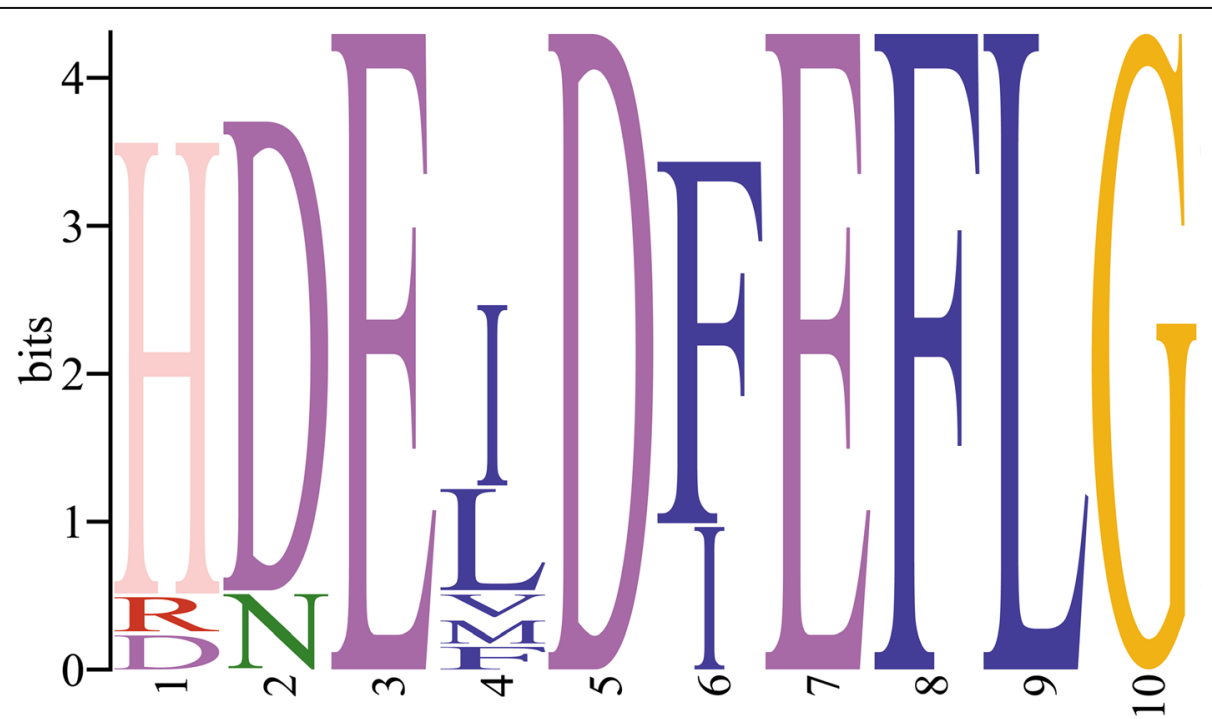

Fig. 4 The logo of catalytic sequence motif (HDEIDFEFLG) of CSXTH proteins. The sequence identity of each binding is composed of the superposition of marker (amino acid residues). The height of the superposition reflects the conservatism of the sequence and the height of each marker reflects the frequency that amino acid residue appears at this position 


\begin{tabular}{|c|c|c|c|}
\hline CsXTH6 & +- & 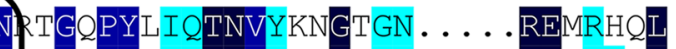 & 145 \\
\hline $\mathrm{CsXTH7}$ & NA HDEIDFEFLGI & RTGOPYILQTNVFTGGK & 142 \\
\hline CsXTH11 & AGTVTAFYMSSD . . GA AHNEFDFEFLGI & NTTGEPYLVOTNVYVNGV & 137 \\
\hline CsXTH14 & FYLQDSNQTNGD JEM. . DFEFLGI & NIGQPYILQTNVIIDG & 143 \\
\hline CsXTH2 & SQ . . GP & ILHTNVFGQG & 140 \\
\hline $\mathrm{CsXTH} 4$ & GP HDEIDFEFLGI & YILHTNVFGQGI & 140 \\
\hline CsXTH5 & HDEII & YTLHTNVYCQGK & 179 \\
\hline CsXTH13 & GSHDEI & YILHTNVF & 142 \\
\hline CsXTH1 & PG HDEID & VLQTNV & 151 \\
\hline CsXTH3 & JEAHPGNHDEID & VLQTNV & 151 \\
\hline CsXTH9 & NEVHPG & QTNVY & 153 \\
\hline CsXTH8 & GDIFEK & NRFQTNVY & 148 \\
\hline $\mathrm{CsXTH} 10$ & IDEID & VRIQTNVY & 142 \\
\hline CsXTH12 & FLGI & RFQTNL & 272 \\
\hline $\mathrm{CsXTH} 6$ & SII & JFKNADYANNF & 205 \\
\hline $\mathrm{CsXTH} 7$ & VT & KDLG & 202 \\
\hline CsXTH11 & & LEHRGIP & 197 \\
\hline CsXTH14 & $T$ & YTAKGVS & 203 \\
\hline $\mathrm{CsXTH2}$ & 年 & NLES IGVR & 200 \\
\hline CsXTH4 & NPQRIIF & JAESVGVP & 200 \\
\hline CsXTH5 & SILWNPHRIVE & JMESKGIP & 239 \\
\hline CsXTH13 & LLWNPQSII & NLKSKGIP & 202 \\
\hline CsXTH1 & JPSE & R. . KSDAT & 208 \\
\hline CsXTH3 & $\mathrm{NE}$ & R. . KSDAT & 208 \\
\hline CsXTH9 & SELI & RYLR. . KSAATH & 210 \\
\hline CsXTH8 & NNNII & RSDAMRGDE & 207 \\
\hline CsXTH1O & $\mathrm{NQII}$ & RTEAMGGD & 201 \\
\hline CsXTH12 & W & KAMGAD & 331 \\
\hline CsXTH 6 & VTNAPFVSSYKI & . . TTTNNWWDQYAAWH & 258 \\
\hline CsXTH7 & SKAPFVASYKSFHVD $\$ C A$ & ASVEAKFCDT . . . . . . Q QGKRWWDQKEFQD & 254 \\
\hline CsXTH11 & NTNAPEVATYTGEEIDAC & CPVTVADADNARRCSSGGQKRYWWDEPTMAE & 257 \\
\hline CsXTH14 & IDWSKGPEIASEKNYKIDAC & WNGDAESCGE . . . . DNSTTNWWQNERENT & 257 \\
\hline $\mathrm{CsXTH} 2$ & WWTQAPETASYRNFNANAC & WSSGASSCSS . . . . SSN . SSNAWLAEEE . . . . & 251 \\
\hline CSXTH4 & WTQAPETASYRNFNANAC & WSSGSSSCSS . . . . SSS . NSNAWFSEQ. & 251 \\
\hline CsXTH5 & WKKAPETASYRNYKADAC & WSEGASSCNSKSPTSNS . IDYLWMSEK . . . . & 294 \\
\hline CsXTH13 & NSQAPETASYRNFSAEAC & PGS . SSSCS . . . . . . . NNAPAWLTQS . . . & 248 \\
\hline CSXTH1 & ZRYQPEIGRYSNEKLG \$C & SDGPSSCNPPSGS $\ldots \ldots$ PSGS $\ldots \ldots$. SG & 256 \\
\hline $\mathrm{CsXTH} 3$ & MYKADYRYQPEIGRYSNEKLG \$C & SDGPSSCNPPSGS . ...P.PSGS . . . . . SG & 256 \\
\hline CsXTH 9 & ADYRYQPFVGMYTNEKAT\&CA & A AYAPRWCRPVSAS . . . . P PYRT . . . . . . GG & 258 \\
\hline CsXTH8 & GKYKVNYKYÄPEVAKETDLSLH\&C & VDPIQEVLSTSCS . . . . EEKNDQLESTNYAR & 262 \\
\hline CsXTH10 & GGKYKVNYKYAPYITEFSDLILH\$CA & VDPIEQS . SLKCD . . . . . HAPN . . . SKSIPG & 252 \\
\hline $\mathrm{CsXTH} 12$ & ATNGGKYKVNYRFQPEVSEFKDLVLQ\$C & VDPIQHLHAPHCD . ..... NSTAALESADESN & 386 \\
\hline
\end{tabular}

Fig. 5 Multiple sequence alignments of 14 CSXTH proteins. The black rounded rectangular frames represent the conserved sequence (HDEIDFEF LG); black rectangular frames represent Cys residues

expression of CsXTH3 decreased under $8 \mathrm{mg} / \mathrm{L}$ and 16 $\mathrm{mg} / \mathrm{L} \mathrm{F}^{-}$treatments. It was notably that there was no significant difference in expressions of CsXTH9 under 8 $\mathrm{mg} / \mathrm{L}$ and $16 \mathrm{mg} / \mathrm{L} \mathrm{F}^{-}$treatments (Fig. 8).
The immunofluorescence labeling in XTHs and activity of XET

The results of immunofluorescence localization of LM10 and LM25 in roots showed that the fluorescence 


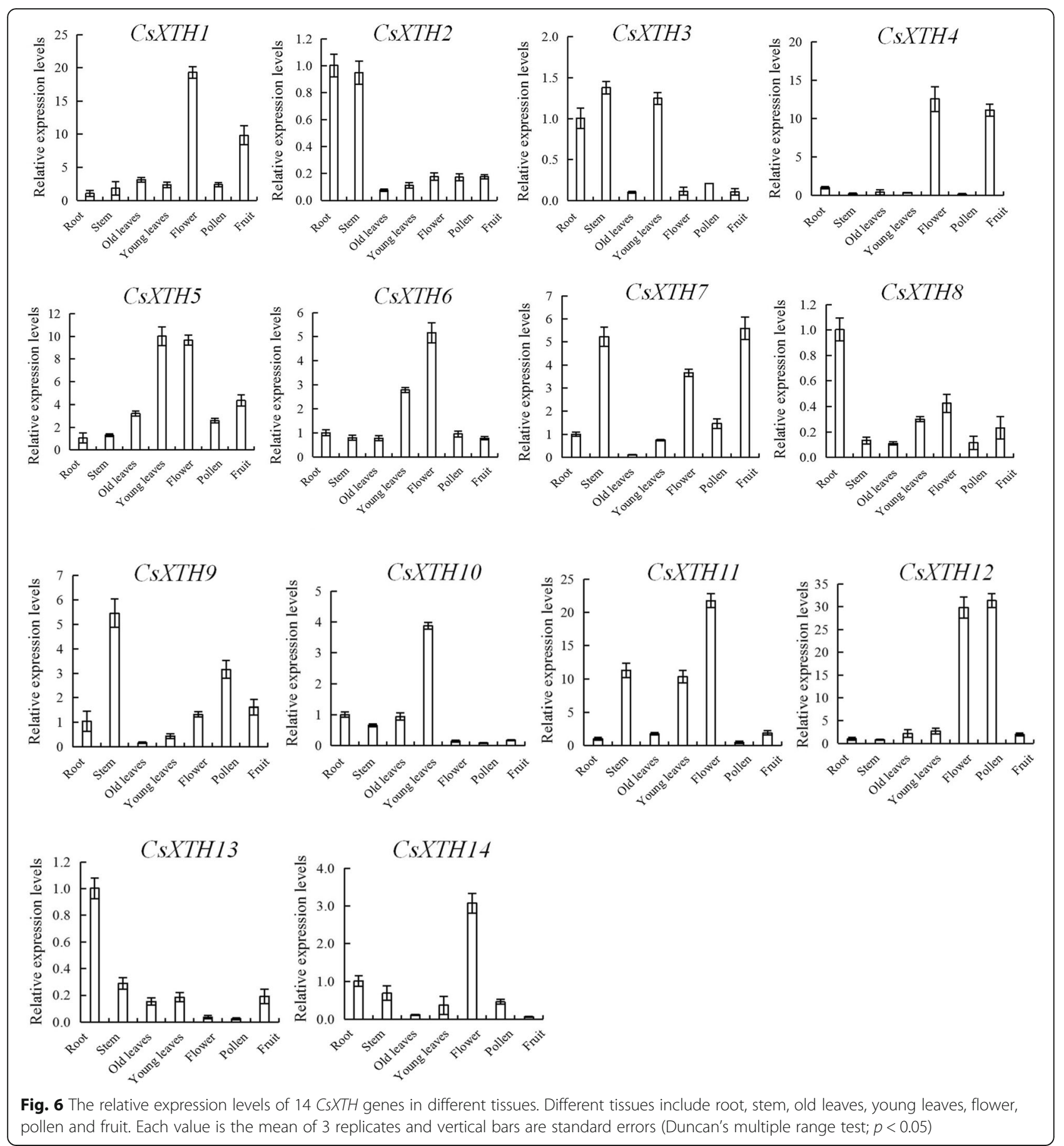

intensity of LM25 was relatively weak but the LM10 was strong without $\mathrm{Al}^{3+}$ or $\mathrm{F}^{-}$treatment. With the increase of $\mathrm{Al}^{3+}$ concentration, the fluorescence intensity of LM25 grew gradually but LM10 declined. The fluorescence intensity of LM25 peaked under $0.4 \mathrm{mM} \mathrm{Al}^{3+}$ and then decreased at $2.0 \mathrm{mM}$ and $4.0 \mathrm{mM} \mathrm{Al}^{3+}$ treatments. It was indicated that $0.4 \mathrm{mM} \mathrm{Al}^{3+}$ treatment might have a positive effect on the formation xyloglucan oligosaccharide by promoting XTH activity, and higher concentrations of $\mathrm{Al}^{3+}$, especially $4.0 \mathrm{mM} \mathrm{Al} l^{3+}$, could probably inhibit XTH activity. Likewise, treatment of 8 $\mathrm{mg} / \mathrm{L} \mathrm{F}^{-}$also might promote XTH activity (Fig. 9).

To confirm the results of immunofluorescence labeling, we determined the XET activity, which could catalyse the transformation of xyloglucan. The results showed that activity of XET in roots gradually increased 


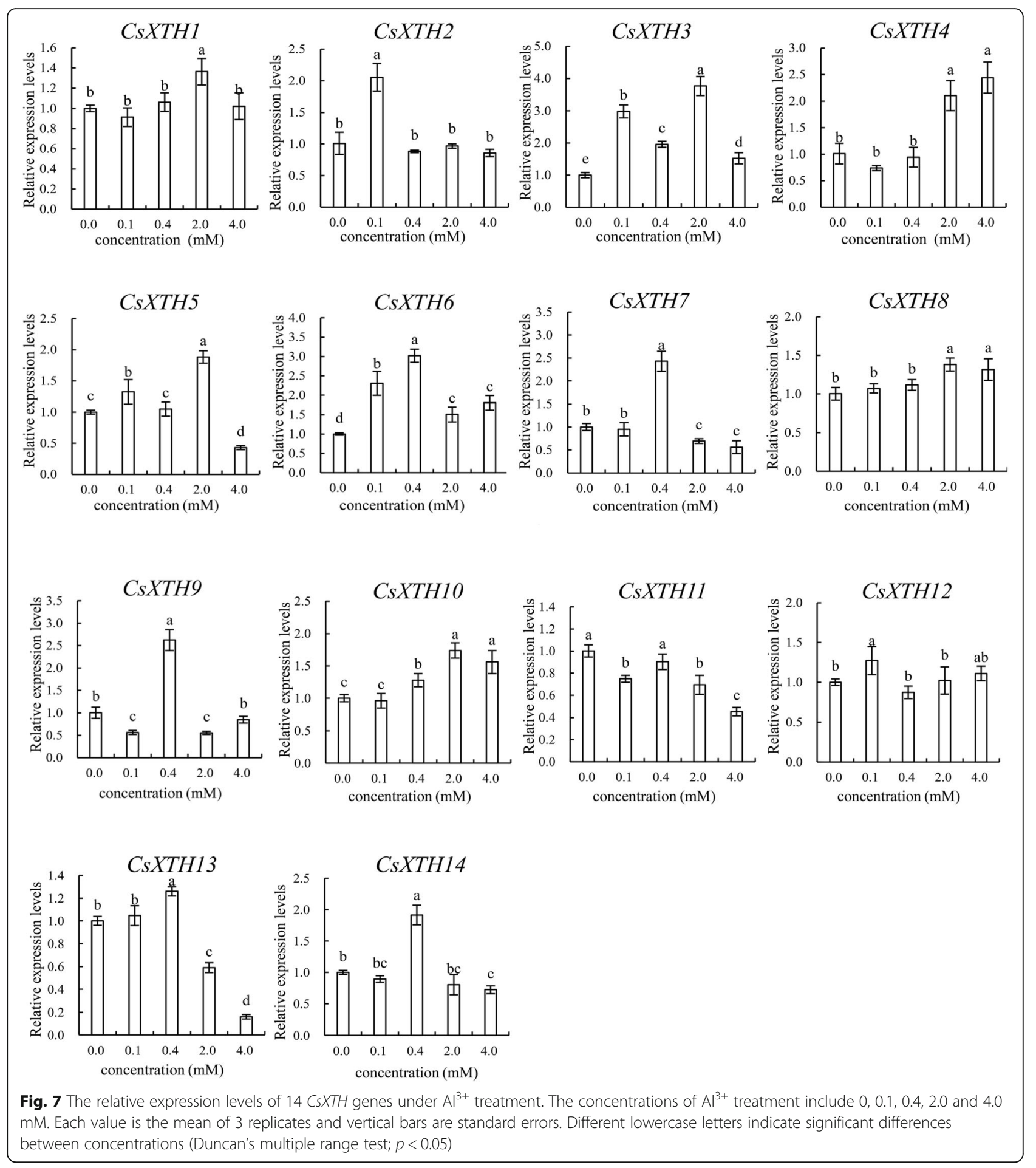

and peaked at $0.4 \mathrm{mM} \mathrm{Al}^{3+}$, then decreased under $\mathrm{Al}^{3+}$ treatments with higher concentrations $(2.0 \mathrm{mM}$ and 4.0 $\mathrm{mM}$ ) (Fig. 10). Similarly, the XET activity significantly increased under $8 \mathrm{mg} / \mathrm{L} \mathrm{F}^{-}$, and then decreased with the increase of $\mathrm{F}^{-}$concentration (Fig. 10).

\section{Discussion}

We identified $14 \mathrm{Cs} X T H$ genes in C. sinensis [22]. CsXTHs were divided into 3 subclasses: I, II and III as other plants (Fig. 1) [12, 13, 25, 26]. Based on the substrate specificities, XTH family belonged to GH16 [27]. 


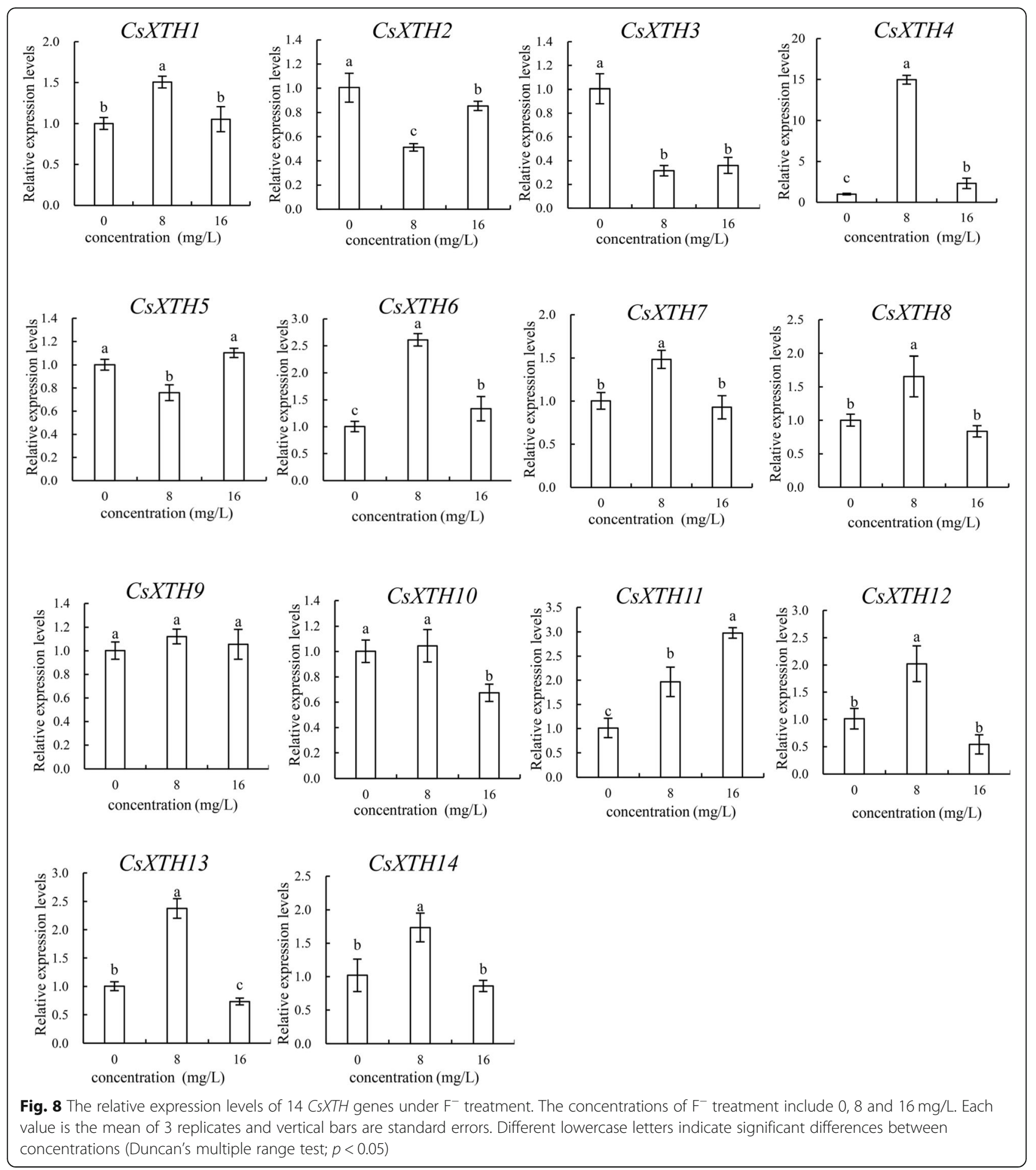

XTHs mainly exerts 2 kinds of catalytic activities: one is XET activity, and the other is XEH activity [28]. Previous studies showed that XET had hydrolytic activity as XEH although XET mainly performed transglucosylase activity [24]. The physicochemical characteristics of CsXTH proteins also illustrated their hydrophilic properties in common (Table 1). Baumann et al. (2007) classified subfamilies III into two subgroups, IIIA (only perform hydrolase activity) and IIIB, respectively, based on their different catalytic activities. The motif analysis showed that all CsXTH proteins contained the catalytic sequence motif (HDEIDFEFLG), which was highly conserved and maintained the activity of XTH, except that there were deviations of 1 or 2 amino acids in some sequences (Fig. 


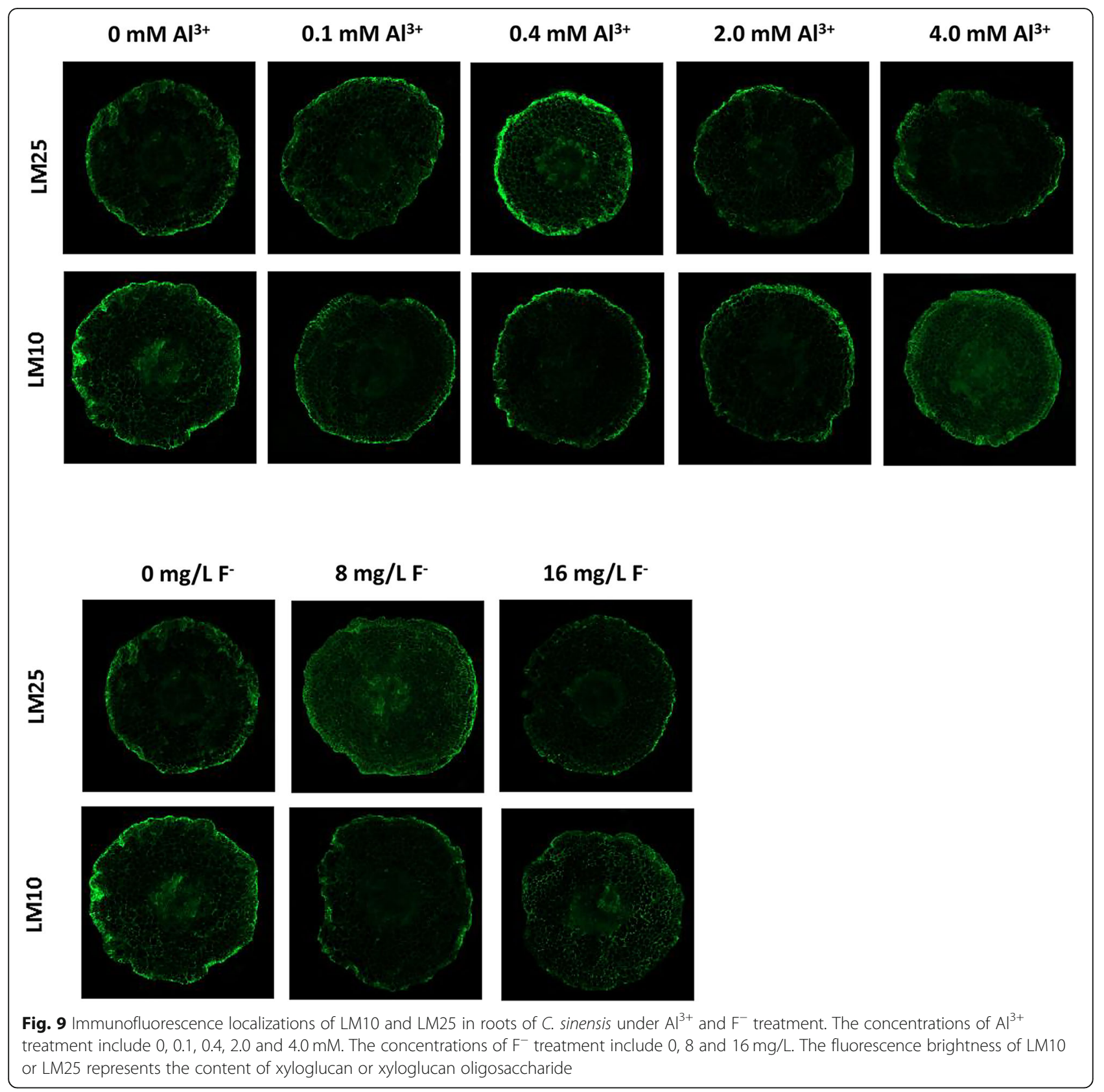

3) [13]. This kind of deviation was also found in XTH family from $A$. thaliana and other species. For example, in Gerbera jamesonii Bolus, the sequence motif became HDELDFEFLG since the active site of isoleucine was replaced by leucine [29]. The results of sequence alignment indicated that each CsXTHs had an N-linked glycosylation site following the catalytic active region except for CsXTHs from subclass IIIA, which suggested that N-linked glycosylation site was an essential structure for XTH to perform XET activity (Fig. 5) [30-32]. Therefore, members of subclass IIIA exhibited only hydrolase activity, whereas the reasons for this phenomenon were still unclear [13, 33]. Moreover, conserved Cys residues were present in C-terminal of sequences of all CsXTH proteins (Fig. 5). Studies had shown that these Cys residues could form disulfide bonds and play an important role in the stability of protein structure [34]. The complexity of conserved motifs indicated that $\mathrm{CsXTH}$ proteins of $C$. sinensis might have multiple biological functions.

The expression levels of $14 \mathrm{Cs} X T H \mathrm{~s}$ genes in different tissues (root, stem, old leaf, young leaf, flower, pollen and fruit) were significantly different (Fig. 6). CsXTH2、CsXTH4、CsXTH5 and CsXTH13 belonged 

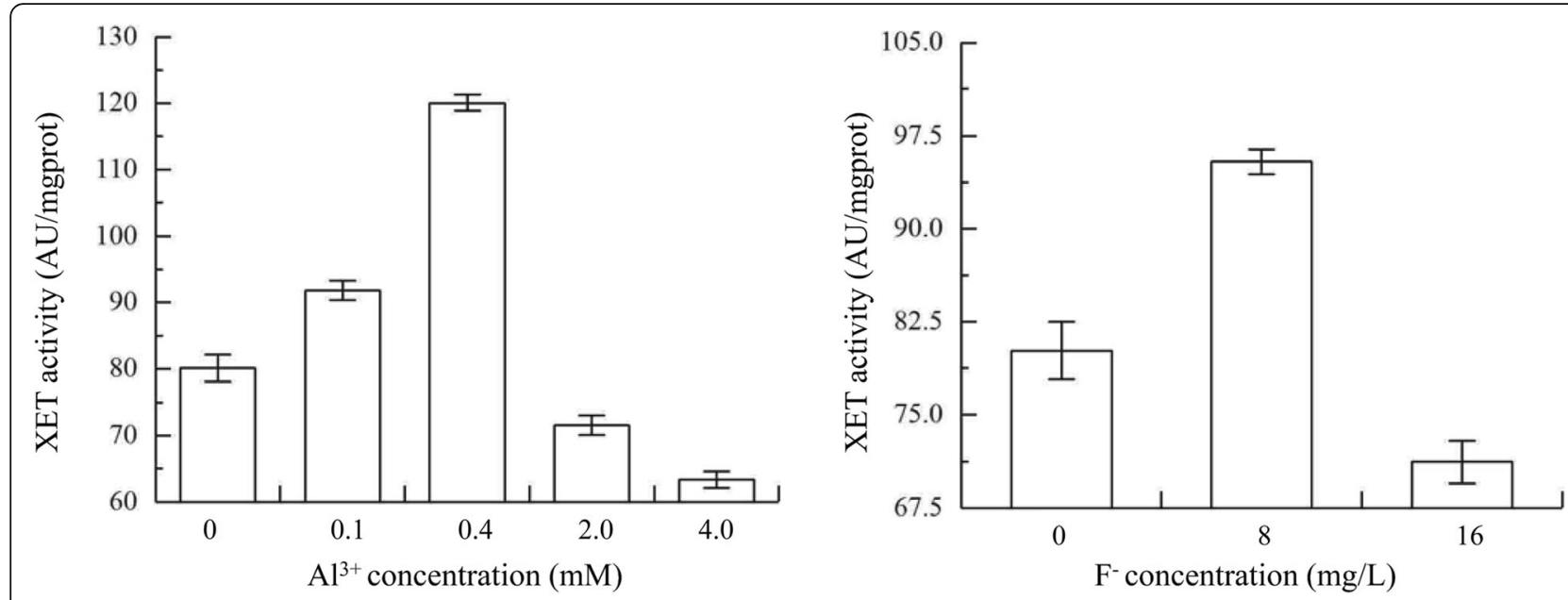

Fig. 10 XET activities in roots of $C$. sinensis under $\mathrm{Al}^{3+}$ and $\mathrm{F}^{-}$treatment. The concentrations of $\mathrm{Al}^{3+}$ treatment include $0,0.1,0.4,2.0$ and $4.0 \mathrm{mM}$. The concentrations of $\mathrm{F}^{-}$treatment include 0,8 and $16 \mathrm{mg} / \mathrm{L}$. Each value is the mean of 3 replicates and vertical bars are standard errors (Duncan's multiple range test; $p<0.05$ )

to the same subclass II as AtXTH17-25 in phylogenetic trees. Studies had shown that AtXTH18, AtXTH19 and AtXTH2O could promote the elongation of hypocotyl of A. thaliana, and AtXTH21 played an important role in the growth of primary roots $[35,36]$. Indeed, CsXTH2 and $C s X T H 13$ were highly expressed in roots, which was predicted that $\mathrm{Cs} X T H 2$ and $\mathrm{Cs} X T H 13$ were functioning in roots [37, 38]. The expressions of CsXTH4 and CsXTH5 in flowers were at high levels, which was similar to the expression of AtXTH21 in flowers [18]. Furthermore, XTHs were closely related to plants growth, so it was reasonable that all CsXTH genes showed low expression levels in old leaves (Fig. 6).

Some studies showed that $\mathrm{Al}$ and $\mathrm{F}$ played a key role in growth and development of $C$. sinensis, which was a hyper-accumulator of $\mathrm{Al}$ and $\mathrm{F}$ [39-41]. The growth and development of $C$. sinensis would be significantly promoted under the treatment of $\mathrm{Al}$ at a low concentration $(0.29-1.19 \mathrm{mM})[42,43]$. There was a serious inhibition with too high concentrations $(>1.85 \mathrm{mM})$ of $\mathrm{Al}[4,44$, 45]. Similarly, there was also a severe inhibition with high concentrations $(>10 \mathrm{mg} / \mathrm{L}$ ) of $\mathrm{F}$ for the growth and metabolism of $C$. sinensis [46, 47].

The expression patterns of $C s X T H s$ under $\mathrm{Al}^{3+}$ and $\mathrm{F}^{-}$ treatments were analyzed to investigate the role of $\mathrm{Cs} X T H$ genes in the process of resisting $\mathrm{Al}$ and $\mathrm{F}$. The results showed that the expression patterns of CsXTHs in the same subclass were similar under $\mathrm{Al}^{3+}$ treatments. For example, $75.0 \%$ of $C s X T H s$ in subclass I and subclass II and $66.7 \%$ of $C s X T H$ genes in subclass IIIA were all upregulated under low concentrations of $\mathrm{Al}^{3+}$ treatments $(0.1 \mathrm{mM}, 0.4 \mathrm{mM})$. This phenomenon might be explained that genes with close genetic relationship had similar functions, which also existed in $X T H$ genes of the same subclass between $C$. sinensis and $A$. thaliana. According to the phylogenetic tree, CsXTH7 and AtXTH5 had a close relative and belonged to the subclass I. The identity of the protein sequences between CsXTH7 and AtXTH5 was as high as $80.7 \%$. The expression level of CsXTH7 reached a peak at $0.4 \mathrm{mM} \mathrm{Al}^{3+}$ (Fig. 7). Studies showed that the expression of AtXTH5 was also significantly upregulated under $\mathrm{Al}$ stress [31]. The expression levels of CsXTH5 and CsXTH13 decreased when $\mathrm{Al}^{3+}$ concentration increased to $4 \mathrm{mM}$ (Fig. 7). Similarly, Yang et al. (2011) reported that the expression levels of AtXTH14 and AtXTH15 were dramatically decreased under the $\mathrm{Al}^{3+}$ stress, resulting in a reduction of XET activity and a significant inhibition of root elongation in A. thaliana, which belonged to subclass II as same as CsXTH5 and CsXTH13 [21]. Therefore, we speculated that the down-regulation of the expressions of $\mathrm{Cs} X T H 5$ and $\mathrm{Cs} X T H 13$ could be involved in the inhibition process of XTH activity under a high concentration of $\mathrm{Al}^{3+}$. In addition, it should be noted that the expression levels of CsXTH4 and CsXTH1O increased under $4.0 \mathrm{mM} \mathrm{Al}^{3+}$ treatment, which might be related to the response to $\mathrm{Al}$ stress in $C$. sinensis.

$C s X T H$ also positively responded to $\mathrm{F}^{-}$treatment. The expressions of CsXTH1, CsXTH4, CsXTH6, CsXTH7, CsXTH8, CsXTH12, CsXTH13 and CsXTH14 reached the highest levels at $8 \mathrm{mg} / \mathrm{L} \mathrm{F}^{-}$(Fig. 8). However, the expression levels of $\mathrm{Cs} X T H 3$ all decreased at different concentrations of $\mathrm{F}^{-}$, which indicated that $\mathrm{F}^{-}$treatment significantly inhibited the expression of CsXTH3. It should be noted that there was no difference in the expression levels of $\mathrm{Cs} X \mathrm{TH} 9$ at different concentrations of 
$\mathrm{F}^{-}$, indicating that $\mathrm{Cs} X T H 9$ was not sensitive to $\mathrm{F}^{-}$treatment. Also, CsXTH2, CsXTH5 and CsXTH11 all showed higher expression levels at $16 \mathrm{mg} / \mathrm{L} \mathrm{F}^{-}$relative to that at $8 \mathrm{mg} / \mathrm{L} \mathrm{F}^{-}$. Therefore, these $3 \mathrm{Cs} X T H$ genes might be able to respond to the stress of high concentrations of $\mathrm{F}^{-}$. The expression patterns of CsXTHs in the same subclass were also similar under $\mathrm{F}^{-}$treatments. For example, $75.0 \%$ of $\mathrm{CsXTHs}$ in subclass I and $66.7 \%$ of $\mathrm{Cs} X T H$ genes in subclass IIIB all had the highest expression levels under $8 \mathrm{mg} / \mathrm{L} \mathrm{F}^{-}$treatments.

Previous studies showed that cell walls had highly complex and dynamic structures composed of cellulose, hemicellulose, pectic polysaccharides and structural proteins, which had strong abilities of accumulating cations [48]. The main components such as pectin and hemicellulose could quickly combine with $\mathrm{Al}^{3+}$, resulting in the accumulation of more than $80-90 \% \mathrm{Al}$ in the cell walls. Therefore, the elasticity and water conductivity of cell walls significantly decreased, and the elongation of roots would be inhibited [4]. The content of xyloglucan in different substitution degrees in roots of C. sinensis was determined by immunofluorescence labeling (Fig. 9). There was more xyloglucan in root tips when the $C$. sinensis were deficient in $\mathrm{Al}$. With the increase of $\mathrm{Al}^{3+}$ concentration, the content of xyloglucan oligosaccharide in roots increased and the content of xyloglucan decreased. When the $\mathrm{Al}^{3+}$ concentration reached $0.4 \mathrm{mM}$, the content of xyloglucan oligosaccharide in roots was the highest. Studies reported that appropriate concentration of $\mathrm{Al}^{3+}$ could not only promote the development of roots, but also increase the chlorophyll content in tea leaves and enhance the net photosynthesis of C. sinensis [49]. The formation of xyloglucan oligosaccharide in roots was gradually inhibited with the further increase of $\mathrm{Al}^{3+}$ concentration. And this inhibition was more obvious at $4.0 \mathrm{mM} \mathrm{Al}^{3+}$, which would not conducive to the cell wall reconstruction and growth of roots [50]. Luo et al. (2006) reported that there was a very serious inhibition on the growth of $C$. sinensis when the $\mathrm{Al}^{3+}$ concentration was greater than $1.85 \mathrm{mM}$ [45]. The treatment of 8 $\mathrm{mg} / \mathrm{L} \mathrm{F}^{-}$promoted the content of xyloglucan oligosaccharide. When the $\mathrm{F}^{-}$concentration reached $16 \mathrm{mg} / \mathrm{L}$, the content of xyloglucan oligosaccharide decreased, which was adverse to cell wall reconstruction and root growth. Although for some plants, the growth and development might be inhibited only when the $\mathrm{F}^{-}$concentration reached $30 \mathrm{mg} / \mathrm{L}$, which was supposed to be caused by species differences [51].

Previous studies showed that there was a good correlation between the activity of XET and the growth rate and the elongation of cell wall $[15,52-54]$. Vissenberg et al. (2005) reported that the activity of XET was high near the starting point of root hair, and it was believed that XET activity was all high in elongation region of roots in various vascular plants [55]. According to the determination results of XET activity in roots, when the $\mathrm{Al}^{3+}$ concentration was $0.4 \mathrm{mM}$ or the $\mathrm{F}^{-}$concentration was $8 \mathrm{mg} / \mathrm{L}$, the XET activity was significantly higher than that of the control group (Fig. 10). However, the activity also decreased if the concentrations of $\mathrm{Al}^{3+}$ or $\mathrm{F}^{-}$continued to rise, which was consistent with the results of immunofluorescence labeling. It was indicated that $0.4 \mathrm{mM} \mathrm{Al}^{3+}$ or $8 \mathrm{mg} / \mathrm{LF}^{-}$could promote the activity of XTH, which might be was beneficial to the cell wall reconstruction and elongation of roots. Based on the results of immunofluorescence labeling and XET activity, it was probable that CsXTHs could get involved in catalyzing the synthesis of xyloglucan oligosaccharide from single xyloglucan molecules, which could loosen cell walls and stimulate the initiation of root hair. However, the direct effect and evidence verifying the functions of CsXTHs still remained to be found and studied.

In summary, the bioinformatics characteristics, expression patterns and the activities of $X T H$ genes in C. sinensis under $\mathrm{Al}^{3+}$ or $\mathrm{F}^{-}$treatments were explored. Under a low concentration of $\mathrm{Al}^{3+}$ or $\mathrm{F}^{-}(0.4$ $\mathrm{mM} \mathrm{Al}^{3+}$ or $8 \mathrm{mg} / \mathrm{LF}^{-}$), the expression levels of CsXTHs, the content of xyloglucan oligosaccharide and the activity of XET were promoted. According to these results, we supposed $0.4 \mathrm{mM} \mathrm{Al}{ }^{3+}$ or $8 \mathrm{mg} / \mathrm{L} \mathrm{F}^{-}$ could stimulate XTH activity by regulating the expressions of CsXTH genes, which might further participate in the transformation of xyloglucan, affect the cell wall reconstruction and ultimately induce root elongation and growth of $C$. sinensis.

\section{Materials and methods Identification and characteristics of XTH gene family in C. sinensis}

A total of 45 sequences with annotations related to XTH genes were searched from the $C$. sinensis transcriptome database (PRJNA315669) [22]. Then, 20 candidate genes of $X T H$ were screened from 45 sequences using the BLAST program of NCBI database online search tool (https://blast.ncbi.nlm.nih.gov/Blast.cgi). All candidate genes with complete domains were analyzed using multi-sequence alignment in ClustalX 1.83 software program (Thompson et al., 1997) to eliminate repeated sequences. Finally, 14 CsXTH genes were obtained for this study and the coding sequences (CDS) of CsXTHs were shown in Additional file 1.

The physicochemical characteristics of $14 \mathrm{CsXTH}$ proteins were obtained from the online tool of ExPASyProtParam (https://web.expasy.org/protparam/). The gene structures were constructed using the online software of GSDS 2.0 (https://gsds.cbi.pku.edu.cn/). 


\section{Phylogenetic tree construction, conserved motif analysis and sequence alignment}

A total of $33 \mathrm{XTH}$ protein sequences of $A$. thaliana were downloaded from The Arabidopsis Information Resource (TAIR) (http://www.arabidopsis.org). A neighborjoining (NJ) phylogenetic tree with a bootstrap value of 1000 was constructed by using MEGA version 6.0 software (Tamura et al., 2011).

The online software MEME (http://meme-suite.org/ tools/meme) was used to analyze the conserved motifs with the parameters of 20 motifs and $\mathrm{E}<1 \mathrm{e}^{-10}$. And the conserved motifs were visualized with TBtools software (https://github.com/CJ-Chen/TBtools). In addition, DNAMAN software (Lynnon Biosoft) was used to multiple alignments of $\mathrm{CsXTH}$ proteins.

\section{Plant materials and treatments}

Annual seedlings of $C$. sinensis cv. Longjing 43 (Nanjing Ya Run Tea Co., Ltd., China) with consistent growth were selected, cleaned and cultivated under hydroponic culture, with a light cycle of $12 \mathrm{~h} / 12 \mathrm{~h}$ (light/dark), a light intensity of $4000 \mathrm{~lx}$, relative humidity of $70 \%$ and temperatures of $25^{\circ} \mathrm{C} / 23^{\circ} \mathrm{C}$ (day/night). The nutrient solutions were prepared according to the method of Wan et al. (2012) and were changed once a week [56]. After the length of new roots exceeded $5 \mathrm{~cm}$, these seedlings were treated respectively with different concentrations of $\mathrm{Al}^{3+}$ and $\mathrm{F}^{-}$. The concentrations of $\mathrm{Al}^{3+}\left(\mathrm{AlCl}_{3}\right)$ treatments included $0 \mathrm{mM}, 0.1 \mathrm{mM}, 0.4 \mathrm{mM}, 2.0 \mathrm{mM}$ and 4.0 $\mathrm{mM}$. And the concentrations of $\mathrm{F}^{-}(\mathrm{NaF})$ treatments contained $0 \mathrm{mg} / \mathrm{L}, 8 \mathrm{mg} / \mathrm{L}$ and $16 \mathrm{mg} / \mathrm{L}$. The new roots were collected after $24 \mathrm{~h}$ of treatments, washed with deionized water and stored at $-80^{\circ} \mathrm{C}$ for total RNA extraction. In order to detect the expression profiles of $X T H$ genes in different tissues, roots, stems, old leaves, young leaves, flowers, pollen and fruits were also collected from seedlings of $C$. sinensis under normal growth conditions with 3 biological replicates and stored at $-80^{\circ} \mathrm{C}$ for total RNA extraction.

\section{Immunofluorescence detection of xyloglucan}

To test the responses of cell walls under different concentrations of $\mathrm{Al}^{3+}$ and $\mathrm{F}^{-}$treatment, we used immunostaining-monoclonal antibodies (LM10 and LM25) (Paul Knox Cell Wall Lab of Leeds University, UK) that could substitute specific degrees of xyloglucan as previously reported [30]. LM10 and LM25 were specific immunostaining sites for xyloglucan. LM10 could indicate xyloglucan, while LM25 could indicate xyloglucan oligosaccharide (mainly XXLG, XLLG, XXLG and XXXG). The fluorescence intensity of LM10 or LM25 represented the content of xyloglucan or xyloglucan oligosaccharide.
The new roots of seedlings were collected and washed with deionized water after $24 \mathrm{~h}$ of treatments of $\mathrm{Al}^{3+}(0$, $0.1,0.4,2.0,4.0 \mathrm{mM})$ and $\mathrm{F}^{-}(0,8,16 \mathrm{mg} / \mathrm{L})$. The transverse sections were sliced at $0-2 \mathrm{~mm}$ from the root tip. The thickness of each section was less than $300 \mu \mathrm{m}$. More than 15 sections were sliced of each treatment group with 3 biological replicates. The sections were fixed into $4 \%$ paraformaldehyde solution at $25^{\circ} \mathrm{C}$ for $2 \mathrm{~h}$ and then washed with PBS (phosphate buffer solution) (pH 7.4). The sections were transferred to PBS containing $0.2 \%$ BSA (bovine serum albumin) and blocked for $0.5 \mathrm{~h}$. Then the sections were washed again with PBS to remove buffer residue. After that these sections were placed in primary antibody (LM10 and LM25) diluted 10 times at $37^{\circ} \mathrm{C}$ for $2 \mathrm{~h}$ and then washed with PBS. FITC (fluorescein isothiocyanate) (Solarbio Science\&Technology, China) was diluted for 50 times for incubation as secondary antibody. The sections were incubated at $37^{\circ} \mathrm{C}$ for $2 \mathrm{~h}$ and then washed with PBS. Finally, the sections were observed and photographed with an Ultra high resolution confocal microscope (Zeiss LSM800, Germany).

\section{Determination of XET activity}

In order to investigate the effect of different concentrations of $\mathrm{Al}^{3+}$ and $\mathrm{F}^{-}$on the activity of XET, we used the double antibody sandwich method to detect the activity of XET [52].

\section{RNA extraction and qRT-PCR analysis}

Total RNA was extracted from samples by using EASYspin RNA Extraction Kit (Adelaide Biological, China), according to the manufacturer's instructions. Total RNA isolated from samples was reverse transcript into cDNA using the PrimeScript ${ }^{\mathrm{tm}}$ RT reagent Kit with gDNA Eraser (Perfect Real Time) kit (Takara Biomedical Technology, China). The expression levels of CsXTH genes were detected on a Quantitative realtime PCR system (Bio-rad CFX96, USA) by using the SYBR Premix Ex Taq kit (Takara Biomedical Technology, China). Each reaction contained $7.2 \mu \mathrm{L}$ $\mathrm{ddH}_{2} \mathrm{O}, 10 \mu \mathrm{L} 2 \times \mathrm{SYBR}$ Premix, $2 \mu \mathrm{L}$ diluted cDNA and $0.4 \mu \mathrm{L}$ gene specific primers. The qRT-PCR conditions were as follows: $95^{\circ} \mathrm{C}$ for $30 \mathrm{~s}, 40$ cycles at $95^{\circ} \mathrm{C}$ for $5 \mathrm{~s}, 60^{\circ} \mathrm{C}$ for $30 \mathrm{~s}$ and $95^{\circ} \mathrm{C}$ for $10 \mathrm{~s}$. Second, $65^{\circ} \mathrm{C}$ for $5 \mathrm{~s}$ and $95^{\circ} \mathrm{C}$ for $5 \mathrm{~s}$. Experiments were repeated with 3 independent biological replicates, and the relative expression levels were analysed by the $2^{-\triangle \Delta C T}$ method. Specific primers for $14 C s X T H$ genes were designed using Primer Premier 5 software (PREMER Biosoft International), and Cs $\beta$-actin was used as an internal reference gene (Table 2). 
Table 2 Primers used for qRT-PCR

\begin{tabular}{|c|c|c|}
\hline Primer & Forward primer sequence & Reverse primer sequence \\
\hline$\beta$-actin & CTCAGTCCAAAAGAGGTATTCT & GTAGAATGTGTGATGCCAGATC \\
\hline CSXTH1 & AAGTGGTTCAAGTCCCTG & CTCTATGTCAATCTCATCGTG \\
\hline CSXTH2 & GATTGGGCAACAAGAGGTG & GCTTTGAGTCCGTGCAGTAA \\
\hline CSXTH3 & GACCACCTTCACCTGGCTAC & TGGATGTGCTTCGTTGTTTG \\
\hline CSXTH4 & ACCCTACTACCGATTTCCA & CAGTCTTCACAAGTCCACCT \\
\hline CSXTH5 & TGTCAAGGCAAGGGTAATAGA & GTAGCCCAATCATCAGCGT \\
\hline CSXTH6 & ATGATACAGGTTGTGGGTTT & ATCTCACGGTTTCCAGTTC \\
\hline CSXTH7 & GGAACAGAACAGGGCAACC & GGAAACCTCACTCCCAAATC \\
\hline CSXTH8 & TTGTTATGACACGGTAAGGTA & ATGCTGGTCTCCATAGTTCTT \\
\hline CSXTH9 & GGTCCTCAGCATCAAAGA & AАTCCTCCCATCCCCAC \\
\hline CSXTH10 & TGCTTCTATCAAACTTCCTGC & СССТCCСАTTGCTTCTGT \\
\hline CSXTH11 & CCACCAAGGACTTCCACTC & AATCGTCTGCGTTCCAAAT \\
\hline CSXTH12 & TATGTTGATGATGTCCCAATAAGAG & AGACGAAGGGCTGGAAGCGGTAGTT \\
\hline CSXTH13 & ACGCTGATGACTGGGCTAC & TाTGACAGGAAGAGGAGGAA \\
\hline CsXTH14 & GGTCAAAGGGTCCATTCATAG & TCTCATTCTGCCACCAGTTAGT \\
\hline
\end{tabular}

\section{Statistical analysis}

The experimental data were analyzed using IBM SPSS statistics 20 and Excel 2007. The difference of results under different concentrations of $\mathrm{Al}^{3+}$ and $\mathrm{F}^{-}$treatment was determined by the multiple of Duncan $(p<0.05)$.

\section{Abbreviations}

XTH: Xyloglucan endotransglycosylase/hydrolases; XET: Xyloglucan endotransglucosylase; XEH: Xyloglucan endohydrolase; Cys: L(+)-Cysteine

\section{Supplementary Information}

The online version contains supplementary material available at https://doi. org/10.1186/s12864-021-08056-5.

Additional file 1: The CDS of CSXTHs. The coding sequences (CDS) of 14 XTH genes from Camellia sinensis.

\section{Acknowledgements}

We thank Dr. Yuehua Ma (Central laboratory of College of Horticulture, Nanjing Agricultural University) for assistance in using Ultra high resolution confocal microscope (Zeiss LSM800, Germany) and Quantitative real-time PCR (Bio-rad CFX96, USA).

\section{Authors' contributions}

Designed experimental, carried out the experiments and analyzed the data: ZCW and CLC. Prepared figures and tables, wrote and reviewed drafts of the manuscript: AQX, XHX and YS. Performed the experiments and revised the manuscript: ZQT, XYL and JYZ. Revised the manuscript: GMW. Conceived and designed the experiments, wrote and revised the manuscript, approved the final draft: YHW. The authors read and approved the final manuscript.

\section{Funding}

This research was funded by the National Natural Science Foundation of China (31972458), the earmarked fund for Jiangsu Agricultural Industry Technology System (JATS[2020]405), the Independent Innovation Project of Jiangsu Province (CX(20)3084)

\section{Availability of data and materials}

The C. sinensis transcriptome datasets analyzed during the current study are available in the National Center for Biotechnology Information (https://www. ncbi.nlm.nih.gov) under the accession number: PRJNA315669. The plant samples used in this study were deposited at Laboratory of Tea breeding and cultivation, Nanjing Agricultural University, Nanjing, China.

\section{Declarations}

\section{Ethics approval and consent to participate}

With the permission to collect, the annual hydroponic seedlings of $C$. sinensis cv. Longjing 43 were collected from Nanjing Ya Run Tea Co., Ltd., China. The study comply with relevant institutional, national, and international guidelines and legislation.

\section{Consent for publication}

Not applicable.

\section{Competing interests}

The authors declare that they have no competing interests.

\section{Author details}

${ }^{1}$ College of Horticulture, Nanjing Agricultural University, Nanjing 210095, China. ${ }^{2}$ Co-innovation Center for Sustainable Forestry in Southern China, Nanjing Forestry University, Nanjing 210037, China.

Received: 30 May 2021 Accepted: 5 October 2021

Published online: 25 October 2021

\section{References}

1. Fung KF, Zhang ZQ, Wong J, Wong MH. Fluoride contents in tea and soil from tea plantations and the release of fluoride into tea liquor during infusion. Environ Pollut. 1999:104(2):197-205.

2. Wong MH, Fung KF, Carr HP. Aluminium and fluoride contents of tea, with emphasis on brick tea and their health implications. Toxicol Lett. 2003: 137(1):111-20.

3. Xiang QC, Liu DH. The effect of fluoride on human body and the research on fluoride accumulation of tea plants. J Tea Commun. 2002;2:34-7 (in Chinese)

4. Yu CP, Pan ZQ, Chen J, Fan DM, Wang XC. Effects of aluminum on growth and physiological characteristics of tea plant. J Plant Nutr Fertil. 2012;18(1): 182-7 (in Chinese).

5. Cai HM, Peng CY, Li CL, Gao Z, Hou RY, Wan XC. Fluoride accumulation and its subcellular distribution in three tea plants. Sci Agric Sin. 2013:46(08): 1668-75. 
6. Zhang XC, Wu HH, Chen LM, Liu LL, Wan XC. Maintenance of mesophyll potassium and regulation of plasma membrane $\mathrm{H}^{+}$-ATPase are associated with physiological responses of tea plants to drought and subsequent rehydration. Crop J. 2018;6(6):611-20.

7. Saladié M, Rose J, Cosgrove DJ, Catalá C. Characterization of a new xyloglucan endotransglucosylase/hydrolase (XTH) from ripening tomato fruit and implications for the diverse modes of enzymic action. Plant J Cell Mol Biol. 2006;47(2):282.

8. Rose J, Braam J, Fry SC, Kazuhiko N. The XTH family of enzymes involved in xyloglucan endotransglucosylation and endohydrolysis: current perspectives and a new unifying nomenclature. Plant Cell Physiol. 2002;43(12):1421-35.

9. Thompson JE, Fry SC. Restructuring of wall-bound xyloglucan by transglycosylation in living plant cells. Plant J. 2001;26(1):23-34.

10. Song L, Valliyodan B, Prince S, Wan J, Nguyen HT. Characterization of the XTH gene family: new insight to the roles in soybean flooding tolerance. Int J Mol Sci. 2018;19(9):2705.

11. Li M, Xie F, He Q, Li J, Liu J, Sun BO, et al. Expression analysis of XTH in stem swelling of stem mustard and selection of reference genes. Genes. 2020; 11(1):113.

12. Yokoyama R, Rose J, Nishitani K. A surprising diversity and abundance of xyloglucan endotransglucosylase/hydrolases in rice. Classification and expression analysis. Plant Physiol. 2004;134(3):1088-99.

13. Baumann MJ, Eklöf JM, Michel G, Kallas-Åsa M, Teeri TT, Czjzek M. Structural evidence for the evolution of xyloglucanase activity from xyloglucan endotransglycosylases: biological implications for cell wall metabolism. Plant Cell. 2007;19(6):1947-63.

14. Edwards M, Dea ICM, Bulpin PV, Reid JSG. Purification and properties of a novel xyloglucan-specific endo-(1-4)- $\beta$-D-glucanase from germinated nasturtium seeds (Tropaeolum majus L.). J Biol Chem. 1986;261 (20):9489-94.

15. Nishitani K, Tominaga R. Endo-xyloglucan transferase, a novel class of glycosyltransferase that catalyzes transfer of a segment of xyloglucan molecule to another xyloglucan molecule. J Biol Chem. 1992;267:21058-64.

16. Campbell P, Braam J. Xyloglucan endotransglycosylases: diversity of genes, enzymes and potential wall-modifying functions. Trends Plant Sci. 1999;4(9): $361-6$.

17. Kallas-Åsa M, Piens K, Denman SE, Henriksson H, Fäldt J, Johansson P, et al. Enzymatic properties of native and deglycosylated hybrid aspen (Populus tremulaxtremuloides) xyloglucan endotransglycosylase $16 \mathrm{~A}$ expressed in Pichia pastoris. Biochem J. 2005;390(1):105-13.

18. Becnel J, Natarajan M, Kipp A, Braam J. Developmental expression patterns of Arabidopsis XTH genes reported by transgenes and genevestigator. Plant Mol Biol. 2006:61(3):451-67.

19. Liu YB, Lu SM, Zhang JF, Liu S, Lu YT. A xyloglucan endotransglucosylase/ hydrolase involves in growth of primary root and alters the deposition of cellulose in Arabidopsis. Planta. 2007:226(6):1547-60.

20. Cho SK, Kim JE, Park JA, Eom TJ, Kim WT. Constitutive expression of abiotic stress-inducible hot pepper CaXTH3, which encodes a xyloglucan endotransglucosylase/hydrolase homolog, improves drought and salt tolerance in transgenic Arabidopsis plants. FEBS Lett. 2006;580(13):3136-44.

21. Yang JL, Zhu XF, Peng YX, Zheng C, Li GX, Liu Y, et al. Cell wall hemicellulose contributes significantly to Al adsorption and root growth in Arabidopsis. Plant Physiol. 2011;154:1885-92.

22. Pan J, Wang W, Li D, Shu Z, Ye X, Chang P, et al. Gene expression profile indicates involvement of NO in Camellia sinensis pollen tube growth at low temperature. BMC Genomics. 2016;17(1):809.

23. Jan $A$, Yang $G$, Nakamura $H$, Ichikawa $H$, Kitano $H$, Matsuoka $M$, et al. Characterization of a xyloglucan endotransglucosylase gene that is upregulated by gibberellin in rice. Plant Physiol. 2004;136(3):3670-81.

24. Henriksson H, Denman SE, Campuzano I, Ademark P, Master ER, Teeri TT, et al. N-linked glycosylation of native and recombinant cauliflower xyloglucan endotransglycosylase 16A. Biochem J. 2004;375(Pt 1):61-73.

25. Ndamukong I, Chetram A, Saleh A, Avramova Z. Wall-modifying genes regulated by the Arabidopsis homolog of trithorax, ATX1: repression of the XTH33 gene as a test case. Plant J. 2009:58(4):541-53.

26. Li Q, Hu A, Dou W, Qi J, Long Q, Zou X, et al. Systematic analysis and functional validation of citrus XTH genes reveal the role of CSXTHO4 in citrus bacterial canker resistance and tolerance. Front Plant Sci. 2019;10(1 109):1-14.

27. Johnasson P, Brumer H, Baumann MJ, Kallas-Åsa M, Henriksson H, Denman $\mathrm{SE}$, et al. Crystal structures of a poplar xyloglucan endotransglycosylase reveal details of transglycosylation acceptor binding. Plant Cell. 2004;16(4): 874-86.
28. Lee J, Burns TH, Light G, Yan S, Fokar M, Kasukabe Y, et al. Xyloglucan endotransglycosylase/hydrolase genes in cotton and their role in fiber elongation. Planta. 2010;232(5):1191-205.

29. Su M, Sun Y, Wang L, Ji X, Zheng B. Cloning and analysis of the CDNA sequence of XTH gene from chrysanthemum morifolium petal. Agric Sci Technol. 2012;13(12):2461-3.

30. Yang JL, Li YY, Zhang YJ, Wu YP, Wu P, Zheng SJ. Cell wall polysaccharides are specifically involved in the exclusion of aluminum from the rice root apex. Plant Physiol. 2008;146:602-11.

31. Wu D, Liu A, Qu X, Liang J, Song M. Genome-wide identification, and phylogenetic and expression profiling analyses, of XTH gene families in Brassica rapa L. and Brassica oleracea L. BMC Genomics. 2020;21(1):782.

32. Niraula PM, Lawrence KS, Klink VP. The heterologous expression of a soybean (Glycine max) xyloglucan endotransglycosylase/hydrolase (XTH) in cotton (Gossypium hirsutum) suppresses parasitism by the root knot nematode Meloidogyne incognita. PLoS One. 2020;15(7):e0235344.

33. Jiang Y, Li Y, Lu C, Tang Y, Jiang X, Gai Y. Isolation and characterization of Populus xyloglucan endotransglycosylase/hydrolase (XTH) involved in osmotic stress responses. Int J Biol Macromol. 2020;155:1277-87.

34. Du LP, Shen X, Chen SL, Hu ZM. Research advances on a key cell wall remodeling enzyme xyloglucan endotransglucosylase/hydrolase (XTH). J Agric Biotechnol. 2010;18(3):604-9 (in Chinese).

35. Yokoyama R. Endoxyloglucan transferase is localized both in the cell plate and secretory pathways destined for the apoplast in tobacco cells. Plant Cell Physiol. 2001;42(3):292-300.

36. Yong L, Liu D, Zhang H, Gao H, Guo X, Wang D, et al. The alpha- and beta-expansin and xyloglucan endotransglucosylase/hydrolase gene families of wheat: molecular cloning, gene expression, and EST data mining. Genomics. 2007;90(4):516-29.

37. Osato Y, Yokoyama R, Nishitani K. A principal role for AtXTH18 in Arabidopsis thaliana root growth: a functional analysis using RNAi plants. J Plant Res. 2006;119(2):153

38. Matsui A, Yokoyama R, Seki M, Ito T, Shinozaki K, Takahashi T, et al. AtXTH27 plays an essential role in cell wall modification during the development of tracheary elements. Plant J. 2005:42(4):525-34.

39. Chenery EM. A preliminary study of aluminum and the tea bush. Plant Soil. 1955:6(2):174-200

40. Ruan J, Ming HW. Accumulation of fluoride and aluminium related to different varieties of tea plant. Environ Geochem Health. 2001;23(1):53-63.

41. Zhang XC, Gao HJ, Yang TY, Wu HH, Zhang ZZ, Wang YM, et al. Anion channel inhibitor NPPB inhibited fluoride accumulation in tea plant (Camellia sinensis) is related to the regulation of $\mathrm{Ca}^{2+}, \mathrm{CaM}$ and depolarization of plasma membrane potential. Int J Mol Sci. 2016;17(1):57.

42. Xie ZM, Ye ZH, Wong MH. Distribution characteristics of fluoride and aluminum in soil profiles of an abandoned tea plantation and their uptake by six woody species. Environ Int. 2001;26(5-6):341-6.

43. Fang $\mathrm{XH}, \mathrm{Wu} \mathrm{C}$. Effects of aluminum on the absorption and distribution of inorganic nutrients in tea plants. China Tea. 1989:4:34-5.

44. Huang DJ, Tan RR, Chen X, Wang HJ, Gong ZM, Wang YP, et al. Transcriptome analysis of root induced by aluminum in tea plants (Camellia sinensis). J Tea Sci. 2019;5:506-20.

45. Luo L, Xie ZL, Liu P, Xu GD, Luo H. Physiological response of tea plants to aluminum toxicity. J Agro Environ Sci. 2006;25(2):305-8 (in Chinese).

46. Zhang L, Li Q, Ma L, Ruan J. Characterization of fluoride uptake by roots of tea plants (Camellia sinensis, (L.) O. Kuntze). Plant Soil. 2013;366(1-2):659-69.

47. Cai HM, Dong YY, Li YY, Li DX, Peng CY, Zhang ZZ, et al. Physiological and cellular responses to fluoride stress in tea (Camellia sinensis) leaves. Acta Physiol Plant. 2016;38(6):1-11.

48. Genovesi V, Fornalã S, Fry SC, Ruel K, Ferrer P, Encina A, et al. ZmXTH1, a new xyloglucan endotransglucosylase/h-ydrolase in maize, affects cell wall structure and composition in Arabidopsis thaliana. J Exp Bot. 2008:59(4):875-89.

49. Wu QY, Zheng WW, Luo L, Liu P, Xu GD. Effects of aluminum on root physiology of tea plant. HUBEl Agric Sci. 2005:3:80-2 (in Chinese).

50. Zhuang WF. Some views on the close planting of tea plant. Tea. 1979;3 (in Chinese).

51. Chen GJ. Fluorine in the environment. Beijing: Science Press; 1990. p. 92-3.

52. Fry SC, Smith RC, Renwick KF, Martin DJ, Hodge SK, Matthews KJ. Xyloglucan endotransglucosylase, a new wall-loosening enzyme activity from plants. Biochem J. 1992;282:821-8.

53. Wu Y, Jeong BR, Fry SC, Boyer JS. Change in XET activities, cell wall extensibility and hypocotyl elongation of soybean seedlings at low water potential. Planta. 2005;220(4):593-601. 
54. Hidvégi N, Gulyás A, Dobránszki J, Teixeira da Silva JA. Mining sequences with similarity to XTH genes in the Solanum tuberosum L. transcriptome: introductory step for identifying homologous XTH genes. Plant Signal Behav. 2020;15(10):1797924.

55. Vissenberg K, Oyama M, Osato Y, Ryusuke Y, Jean-Pierre V, Kazuhiko N. Differential expression of AtXTH17, AtXTH18, AtXTH19 and AtXTH20 genes in Arabidopsis roots. Physiological roles in specification in cell wall construction. Plant Cell Physiol. 2005;46(1):192-200.

56. Wan Q, Xu RK, Li XH. Proton release by tea plant (Camellia sinensis L.) root affected by nutrient solution concentration and pH. Plant Soil Environ. 2012; 58(9):429-34.

\section{Publisher's Note}

Springer Nature remains neutral with regard to jurisdictional claims in published maps and institutional affiliations.

Ready to submit your research? Choose BMC and benefit from:

- fast, convenient online submission

- thorough peer review by experienced researchers in your field

- rapid publication on acceptance

- support for research data, including large and complex data types

- gold Open Access which fosters wider collaboration and increased citations

- maximum visibility for your research: over $100 \mathrm{M}$ website views per year

At BMC, research is always in progress.

Learn more biomedcentral.com/submissions 